\title{
Neoantigen-based Glioblastoma Vaccine
}

National Cancer Institute

\section{Source}

National Cancer Institute. Neoantigen-based Glioblastoma Vaccine. NCI Thesaurus.

Code C118960.

A peptide-based, personalized glioblastoma cancer vaccine consisting of patient-specific glioblastoma derived immunogenic mutated epitopes (neoantigens), with potential immunomodulating and antineoplastic activities. Vaccination with the neoantigen-based glioblastoma vaccine stimulates the host immune system to mount a cytotoxic $T$ lymphocyte $(C T L)$ response against tumor cells expressing the neoantigens, which results in tumor cell lysis. Neoantigens are tumor-specific antigens derived from mutated proteins that are present only in a specific tumor. 